\title{
Modeling mortality risk effects of cigarettes and smokeless tobacco: results from the National Health Interview Survey Linked Mortality File Data
}

\author{
Esther Salazar ${ }^{*}$, Chunfeng Ren, Brian L. Rostron and Ghideon Solomon
}

\begin{abstract}
Background: Cigarettes and smokeless tobacco (SLT) products are among a wide range of tobacco products that are addictive and pose a significant health risk. In this study, we estimated smoking- and SLT use-related mortality hazard ratios (HRs) among U.S. adults by sex, age group, and cause of death, for nine mutually exclusive categories of smoking and/or SLT use.

Methods: We used data from the public-use National Health Interview Survey Linked Mortality with mortality follow-up through 2015. We used Cox proportional hazard models to estimate mortality HRs, adjusted by race/ ethnicity, education, poverty level, body mass index, and tobacco-use status.

Results: With never users as reference group, HRs for smoking-related diseases for male exclusive current smokers aged 35-64 and 65+ were 2.18 (95\% confidence interval [Cl]: 1.79-2.65), and 2.45 (95\% Cl: 2.14-2.79), respectively. Similar significant HR estimates were found for females and for all-cause mortality (ACM) and other-cause mortality (OCM) outcomes. HRs for exclusive current SLT users were only significant for males aged 35-64 for ACM (HR: 2.04, 95\% Cl: 1.27-3.27) and OCM (HR: 2.80, 95\% Cl: 1.50-5.25). HRs for users who switched from cigarettes to SLT products were significant for males aged 65+ for smoking-related diseases (HR: 2.06, 95\% Cl: 1.47-2.88), SLT-related diseases (HR: 1.99, 95\% Cl: 1.36-2.89), and ACM (HR: 1.63, 95\% Cl: 1.21-2.19).

Conclusions: Male exclusive current SLT users aged 35-64 had a significant HR for ACM and OCM outcomes, suggesting that deaths not attributed to SLT use could be contributing to the ACM elevated HR for exclusive current SLT users.
\end{abstract}

Keywords: Mortality risk, Cigarettes, Smokeless tobacco

\section{Background}

Cigarettes and smokeless tobacco (SLT) products are among a wide range of tobacco products that are addictive and pose a significant health risk in current and former users [1, 2]. In the United States (U.S.), although cigarette smoking rates among adults have decreased

* Correspondence: Esther.Salazar@fda.hhs.gov

Center for Tobacco Products, U.S. Food and Drug Administration, 11785 Beltsville Dr., Calverton, MD 20705, USA (from $23.1 \%$ in 2000 to $13.9 \%$ in 2018 ) [3, 4], sales, advertising and promotion of SLT have increased [5] primarily among male adults. Since mortality risk estimates associated with cigarettes and SLT use can change over time, and previous estimates for SLT have been limited by relatively small sample size, updated mortality risk estimates associated with the use of cigarettes and SLT are warranted to assess the mortality impact in the U.S. population and to inform regulatory activities.

(c) The Author(s). 2021, corrected publication 2021. Open Access This article is licensed under a Creative Commons Attribution 4.0 International License, which permits use, sharing, adaptation, distribution and reproduction in any medium or format, as long as you give appropriate credit to the original author(s) and the source, provide a link to the Creative Commons licence, and indicate if changes were made. The images or other third party material in this article are included in the article's Creative Commons licence, unless indicated otherwise in a credit line to the material. If material is not included in the article's Creative Commons licence and your intended use is not permitted by statutory regulation or exceeds the permitted use, you will need to obtain permission directly from the copyright holder. To view a copy of this licence, visit http://creativecommons.org/ licenses/by/4.0/. The Creative Commons Public Domain Dedication waiver (http://creativecommons.org/publicdomain/zero/1. 0/) applies to the data made available in this article, unless otherwise stated in a credit line to the data. 
Although smoking-attributable mortality risks have been extensively studied over several decades [6-8], comparable estimates for SLT have been more limited. Henley et al. [9] published estimates of mortality hazard ratios (HRs) for SLT users among participants in the American Cancer Society's Cancer Prevention Studies I and II with enrollment in 1959 and 1982, respectively. They found increased risk among SLT users for both all-cause mortality and specific causes including heart disease, stroke, and to some extent cancer. More recently, Timberlake et al. [10] conducted a survival analysis using data from participants in the Tobacco Use Supplement to the Current Population Survey from 1985 to 2011 contained in the National Longitudinal Mortality Study (NLMS). They also found higher mortality risk for coronary heart disease among SLT users. Similar studies have been conducted using NLMS and National Health Interview Survey (NHIS)-Linked Mortality Files (LMF) [11-13].

This study aims to estimate mortality rates and mortality risk effects among current and former users of cigarettes and SLT products in the U.S. by sex, age group and cause of death using the most updated NHIS data linked with death certificate records from the National Death Index (NDI). To date, the latest released NHISLMF provide mortality follow-up data from the date of survey participation through December 31, 2015 [14]. For years in which there are tobacco use behavior data associated with both cigarettes and SLT use (1987, 1991, 1992, 1994, 1998, 2000, 2005, 2010, 2012-2014), we estimated mortality risks for nine mutually exclusive tobacco use categories.

This study has advantages compared to similar studies conducted using the NHIS-LMF data. For instance, Fisher et al. [11] used the NHIS-LMF data with mortality follow-up through December 31, 2011 to estimate mortality risks for smokers and SLT users; however, they reported results for adults (sex-combined) aged 18+. Also, Rodu et al. [12] analyzed the NHIS-LMF 2015 data, and reported mortality risks for only one analysis group of males aged 40-79, assuming that tobacco use did not change over participants' lifetimes. We extended these two studies using NHIS-LMF 2015 data, providing updated mortality risk estimates by sex and age group, and assuming a 10-year mortality follow-up to reduce misclassification of participants' tobacco-use status during the survival time.

\section{Methods}

\section{Study population}

We used the public-use 2015 NHIS-LMF datasets that contain mortality follow-up data of U.S. adult civilian noninstitutionalized population aged $18+$ in which participants were followed from the date of survey participation through December 31, 2015. We pooled data from 11 survey years $(1987,1991,1992,1994,1998$, 2000, 2005, 2010, 2012-2014) where smoking and SLT (chewing tobacco, snuff, dip, snus, or dissolvable tobacco) use were self-reported (Additional file 1: Table S1, shows all reported SLT products during the study period). To account for changes in the sample design across pooled NHIS data, we adjusted the analytic weights by dividing each sample weight by the number of pooled years [15].

\section{Measures}

\section{Tobacco use status}

We used participants' self-reported tobacco use status at the time of interview to define current, former, and never users of cigarettes and SLT as follows. Never cigarette smokers had never smoked 100 cigarettes in their lifetime. Current cigarette smokers had smoked 100 cigarettes in their lifetime, and at the time of interview had smoked every day or some days or had quit smoking within the past 2 years (under the assumption that recent quitters have similar health risk as current smokers) [16, 17]. Former cigarette smokers had smoked 100 cigarettes in their lifetime but had quit smoking more than 2 years prior to the survey. Never SLT users had never used SLT or used it less than 20 times in their lifetime. Current SLT users had used it at least once or at least 20 times and used it every day or some days at the time of interview. Former SLT users had used it at least once or at least 20 times and did not use it at all at the time of interview. We defined nine mutually exclusive tobacco user groups who did not use any other tobacco products including pipe, hookah, e-cigarettes, bidi, and cigars (see Additional file 1: Table S1): (1) current smokers and SLT users (dual current users); (2) current smokers and former SLT users; (3) current smokers and never SLT users (exclusive current smokers); (4) former smokers and current SLT users; (5) former smokers and former SLT users; (6) former smokers and never SLT users (exclusive former smokers); (7) never smokers and current SLT users (exclusive current SLT users); (8) never smokers and former SLT users (exclusive former SLT users); (9) never users of both cigarettes and SLT.

\section{Cause of death}

We used the underlying leading cause of death variable (UCOD_LEADING) [18] to derive five mortality outcomes by combining cause-specific death categories, as described in Additional file 1: Table S2: (1) all-cause mortality (ACM), (2) smoking-related diseases [17, 19], (3) SLT-related diseases, (4) lung diseases excluding lung cancer, and (5) other-cause mortality (OCM). 


\section{Demographic characteristics}

We considered the following individual and socioeconomic characteristics: age, sex, race/ethnicity (Hispanic, non-Hispanic white, non-Hispanic black, non-Hispanic other), education (some high school and below, high school graduate or equivalent, some college and above), poverty level $[20,21]$ (below poverty threshold, at or above poverty threshold), and body mass index (BMI; unit: $\mathrm{kg} / \mathrm{m}^{2}$; categories: underweight, $\mathrm{BMI}<18.5$; normal weight, $\quad 18.5 \leq \mathrm{BMI}<25 ; \quad$ overweight, $25 \leq \mathrm{BMI}<30$; obese, $\mathrm{BMI} \geq 30$ ).

\section{Analytic sample}

The initial sample size included 266,561 NHIS participants aged $18+$ at the time of interview, after excluding 81,983 participants with missing information on cigarette use, SLT use or ever users of other tobacco products (including pipe, hookah, e-cigarettes, bidi, and cigars). From this data, the mortality follow-up period ranged from 0 to 29 years $($ median $=10.4$ years, mean $=$ 12.1 years, standard deviation $=9.3$ years). Since participants' tobacco-use status was only provided at the time of interview and it might change during the follow-up period, for sensitivity analysis purposes we truncated (right-censored) the follow-up period to a maximum of $5,10,15,20$, and up to 29 years (maximum follow-up), under the assumption that tobacco-use status remained the same during the survival time. We only reported results from the 10-year follow-up data since results from the sensitivity analysis did not differ substantially. Previous analyses indicate that middle-aged and older adults are most likely to have long-term established patterns of tobacco use or never use, and current tobacco users are beginning to die from tobacco use-related diseases [12, 22]; thus, we restricted our analyses to participants aged $35+$. Our final analytic sample included 220,891 female and male participants aged $35+$ with complete information on cigarette and SLT use and mortality follow-up data, including 22,515 all-cause deaths during the 10year follow-up period, with 5571 deaths among 51,373 current smokers and 486 deaths among 3324 current SLT users.

\section{Statistical analysis}

We analyzed the data in 2019-2020. For each tobaccouse status and mortality outcome, we calculated death rates per 100,000 person-years as the ratio of "number of weighted reported deaths" to "weighted person-years survived" [23, 24], as described in the Additional file 1.

We used Cox proportional hazard models to estimate mortality HRs by tobacco-use status, age group and sex, assuming that tobacco-use status remains the same during follow-up, and accounting for the data's complex survey design $[25,26]$. Models were fitted independently by sex, age group, and cause of death, and adjusted by race/ethnicity, education, poverty level, BMI, and tobacco-use status. In all models, "never tobacco users" was used as reference group to estimate mortality HRs. Although we acknowledged that smoking and SLT use behavior characteristics, such as duration and intensity of use, are important predictors for risk mortality $[8,27]$, they were not included as covariates in our models because of the lack of data for SLT users during the study period. We reported HRs, with their corresponding 95\% CIs, by tobacco-use status, sex and age groups (35-64 and $65+$ ). We checked the proportional hazard assumption by comparing two Cox models, one specifying a covariate with time-independent effects (as described above) and one adding a time-dependent interaction term assuming that the effect of a covariate varies over time [28], while still accounting for the data's complex survey design. To avoid multicollinearity when adding the interaction terms, we opted for multiplying the timeindependent covariate by $(\log t-\operatorname{mean}(\log t))$ where $t$ denotes the follow-up time. The validity of the proportionality assumption was assessed by testing the hypothesis that all coefficients associated with the timedependent term are zero, using the Rao-Scott likelihoodratio test for complex survey $[29,30]$.

We also conducted a sensitivity analysis comparing results from five follow-up periods: $5,10,15,20$, and up to 29 years. We opted for reporting results from the 10year follow-up data for the following two reasons: [1] as a reference, we chose the median follow-up period (10.4 years), under the assumption that, up to 10 years of survival time, tobacco-use status reported at the time of interview remained the same [2]; although the HR point estimates for exclusive SLT users slightly decreased as follow-up period increased, the HR estimates (and their corresponding 95\% CIs) for other tobacco-use statuses were not substantially different across the follow-up periods (see Additional file 1: Table S8).

We used SAS 9.4 software [31] for data preparation and descriptive analysis, and R 3.6.1 [32] for complex survey data analysis using the survey package, version $3.36[33,34]$.

\section{Results}

\section{Descriptive analysis}

Table 1 shows weighted demographic and socioeconomic characteristics of participants aged $35+$ at the time of interview, by tobacco-use status (Additional file 1: Table S3, shows the corresponding 95\% CIs estimated using the modified Wilson method [35, 36]). The average age for exclusive current SLT users (53.68, 95\% CI: 52.63-54.73) was higher than for exclusive current smokers (51.41, 95\% CI: 51.24-51.58). Dual users (current smokers and SLT users) had the lowest average age $(48.75,95 \%$ CI: 
Table 1 Demographic and socioeconomic characteristics (weighted estimates) ${ }^{a}$ for NHIS participants ${ }^{b}$ aged $35+$ at the time of interview

\begin{tabular}{|c|c|c|c|c|c|c|c|c|c|c|}
\hline \multirow[t]{2}{*}{ Variables } & \multicolumn{3}{|c|}{ Current Smokers } & \multicolumn{3}{|c|}{ Former Smokers } & \multicolumn{2}{|c|}{ Never Smokers } & \multirow{2}{*}{$\begin{array}{l}\text { Never } \\
\text { Tobacco } \\
\text { Users }\end{array}$} & \multirow[t]{2}{*}{ All } \\
\hline & $\begin{array}{l}\text { Current } \\
\text { SLT Users }\end{array}$ & $\begin{array}{l}\text { Former } \\
\text { SLT Users }\end{array}$ & $\begin{array}{l}\text { Never SLT } \\
\text { Users }\end{array}$ & $\begin{array}{l}\text { Current } \\
\text { SLT Users }\end{array}$ & $\begin{array}{l}\text { Former } \\
\text { SLT Users }\end{array}$ & $\begin{array}{l}\text { Never SLT } \\
\text { Users }\end{array}$ & $\begin{array}{l}\text { Current } \\
\text { SLT Users }\end{array}$ & $\begin{array}{l}\text { Former } \\
\text { SLT Users }\end{array}$ & & \\
\hline Mean age in years & 48.75 & 48.99 & 51.41 & 56.29 & 57.53 & 60.19 & 53.68 & 50.51 & 54.97 & 55.23 \\
\hline \multicolumn{11}{|l|}{ Sex $\%$} \\
\hline Male & 79.11 & 75.25 & 37.56 & 92.08 & 79.68 & 38.23 & 75.81 & 77.10 & 32.53 & 36.25 \\
\hline female & 20.89 & 24.75 & 62.44 & 7.92 & 20.32 & 61.77 & 24.19 & 22.90 & 67.47 & 63.75 \\
\hline \multicolumn{11}{|l|}{ Race/ethnicity \% } \\
\hline Hispanic & 3.16 & 5.18 & 9.24 & 1.30 & 5.62 & 9.15 & 2.14 & 4.84 & 14.00 & 11.85 \\
\hline $\begin{array}{l}\text { Non-Hispanic } \\
\text { white }\end{array}$ & 85.38 & 80.95 & 73.51 & 88.25 & 85.54 & 79.28 & 77.35 & 82.23 & 67.47 & 71.37 \\
\hline $\begin{array}{l}\text { Non-Hispanic } \\
\text { black }\end{array}$ & 9.80 & 11.33 & 13.5 & 7.80 & 7.58 & 8.39 & 18.00 & 11.10 & 12.00 & 11.56 \\
\hline $\begin{array}{l}\text { Non-Hispanic } \\
\text { other }\end{array}$ & 1.66 & 2.54 & 3.74 & 2.65 & 1.27 & 3.18 & 2.52 & 1.83 & 6.54 & 5.23 \\
\hline \multicolumn{11}{|l|}{ Education $\%$} \\
\hline $\begin{array}{l}\text { Less than high } \\
\text { school }\end{array}$ & 31.85 & 23.05 & 22.31 & 33.82 & 23.66 & 16.71 & 36.76 & 14.18 & 16.17 & 17.70 \\
\hline $\begin{array}{l}\text { High school } \\
\text { diploma }\end{array}$ & 35.88 & 40.96 & 38.64 & 32.42 & 32.75 & 30.33 & 29.93 & 23.06 & 26.83 & 29.80 \\
\hline $\begin{array}{l}\text { Some college and } \\
\text { higher }\end{array}$ & 32.28 & 35.75 & 38.5 & 33.5 & 43.48 & 52.46 & 33.04 & 62.44 & 56.36 & 51.91 \\
\hline Missing & 0.00 & 0.24 & 0.56 & 0.26 & 0.11 & 0.50 & 0.28 & 0.32 & 0.64 & 0.58 \\
\hline \multicolumn{11}{|l|}{ Poverty level $\%$} \\
\hline $\begin{array}{l}\text { At or above } 100 \% \\
\text { threshold }\end{array}$ & 76.94 & 76.96 & 73.05 & 78.77 & 83.89 & 79.29 & 72.32 & 82.39 & 77.99 & 77.39 \\
\hline $\begin{array}{l}\text { Below 100\% } \\
\text { threshold }\end{array}$ & 13.03 & 16.11 & 14.08 & 12.13 & 6.39 & 7.01 & 14.63 & 7.38 & 8.62 & 9.39 \\
\hline Missing & 10.02 & 6.93 & 12.87 & 9.1 & 9.73 & 13.7 & 13.05 & 10.23 & 13.39 & 13.22 \\
\hline \multicolumn{11}{|c|}{ Body mass index $\left(\mathrm{kg} / \mathrm{m}^{2}\right) \%$} \\
\hline $\begin{array}{l}\text { Underweight } \\
(<18.5)\end{array}$ & 1.60 & 2.58 & 2.96 & 0.96 & 0.46 & 1.22 & 1.04 & 0.50 & 1.53 & 1.71 \\
\hline $\begin{array}{l}\text { Normal weight } \\
(18.5-24.9)\end{array}$ & 30.58 & 31.06 & 40.94 & 21.39 & 21.56 & 33.1 & 21.61 & 19.66 & 34.84 & 35.19 \\
\hline $\begin{array}{l}\text { Overweight } \\
(25.0-29.9)\end{array}$ & 38.56 & 41.31 & 32.14 & 45.76 & 42.77 & 35.57 & 39.64 & 43.31 & 34.14 & 34.35 \\
\hline Obese $(30+)$ & 27.27 & 24.00 & 21.25 & 30.68 & 33.26 & 26.85 & 35.49 & 35.63 & 25.94 & 25.49 \\
\hline Missing & 1.99 & 1.05 & 2.72 & 1.21 & 1.95 & 3.27 & 2.22 & 0.89 & 3.55 & 3.27 \\
\hline
\end{tabular}

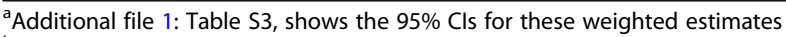

bexcluding participants with missing tobacco-use status, poly-users, and users of other tobacco products including pipe, hookah, e-cigarettes, bidi, and cigars.

Survey years: 1987, 1991, 1992, 1994, 1998, 2000, 2005, 2010, and 2012-2014

47.51-49.98) while exclusive former smokers had the highest average age (60.19, 95\% CI: 59.97-60.41). Exclusive current SLT users, along with exclusive current and former smokers, were more likely to be non-Hispanic white and have less education (less than high school or high school diploma) and higher poverty level (at or above $100 \%$ poverty threshold). Never tobacco users tend to have higher education (some college and higher) than dual and exclusive current smokers and SLT users.
Exclusive current SLT users tend to be obese (35.49, 95\% CI: 31.58-39.6) compared to exclusive current smokers (21.25, 95\% CI: 20.66-21.85).

\section{Cause-specific mortality risk effects}

Table 2 shows death rates (per 100,000 person-years) with their corresponding 95\% CIs, and unweighted number of deaths by tobacco-use status and leading cause of death for both females and males aged 35+. For ACM, 
Table 2 Death rates (per 100,000 person-years), lower and upper limits (LL, UL) of the 95\% Cls, and number of deaths by leading cause of death among adults aged 35+ using a maximum of 10-year follow-up ${ }^{\text {a }}$

\begin{tabular}{|c|c|c|c|c|c|c|c|c|c|c|}
\hline & \multicolumn{3}{|c|}{ Current Smokers } & \multicolumn{3}{|c|}{ Former Smokers } & \multicolumn{2}{|c|}{ Never Smokers } & \multirow{2}{*}{$\begin{array}{l}\text { Never } \\
\text { Tobacco } \\
\text { Users }\end{array}$} & \multirow[t]{2}{*}{ All } \\
\hline & $\begin{array}{l}\text { Current } \\
\text { SLT users }\end{array}$ & $\begin{array}{l}\text { Former } \\
\text { SLT users }\end{array}$ & $\begin{array}{l}\text { Never SLT } \\
\text { users }\end{array}$ & $\begin{array}{l}\text { Current } \\
\text { SLT users }\end{array}$ & $\begin{array}{l}\text { Former } \\
\text { SLT users }\end{array}$ & $\begin{array}{l}\text { Never SLT } \\
\text { users }\end{array}$ & $\begin{array}{l}\text { Current } \\
\text { SLT users }\end{array}$ & $\begin{array}{l}\text { Former } \\
\text { SLT users }\end{array}$ & & \\
\hline $\begin{array}{l}\text { Number of } \\
\text { Participants }\end{array}$ & 810 & 1976 & 48,587 & 728 & 1512 & 36,755 & 1786 & 1949 & 126,788 & 220,891 \\
\hline \multicolumn{11}{|c|}{ All-cause mortality } \\
\hline Rate & 1260.2 & 1486.7 & 1467.3 & 2362.1 & 1954.9 & 2046.4 & 1839.5 & 918.8 & 1174.3 & 1398.0 \\
\hline 95\% Cl: LL & 920.2 & 1235.8 & 1411.8 & 1773.2 & 1609.8 & 1971.0 & 1508.0 & 722.9 & 1145.1 & 1371.7 \\
\hline 95\% Cl: UL & 1600.1 & 1737.6 & 1522.8 & 2951.0 & 2300.0 & 2121.8 & 2171.0 & 1114.8 & 1203.6 & 1424.3 \\
\hline Deaths & 81 & 228 & 5262 & 131 & 229 & 5199 & 274 & 154 & 10,957 & 22,515 \\
\hline \multicolumn{11}{|c|}{ Smoking-related diseases ${ }^{b}$} \\
\hline Rate & 926.8 & 893.5 & 963.9 & 1712.3 & 1343.4 & 1249.1 & 984.5 & 523.9 & 669.6 & 841.5 \\
\hline 95\% Cl: LL & 646.5 & 709.4 & 921.3 & 1190.1 & 1075.7 & 1191.0 & 780.0 & 374.8 & 648.5 & 821.8 \\
\hline 95\% Cl: UL & 1207.1 & 1077.6 & 1006.5 & 2234.5 & 1611.0 & 1307.3 & 1189.0 & 673.1 & 690.6 & 861.3 \\
\hline Deaths & 63 & 144 & 3644 & 94 & 169 & 3385 & 173 & 95 & 6630 & 14,397 \\
\hline
\end{tabular}

SLT-related diseases ${ }^{c}$

$\begin{array}{lllllllllll}\text { Rate } & 840.2 & 723.1 & 806.7 & 1497.4 & 1173.7 & 1062.2 & 935.3 & 488.4 & 614.4 & 740.8 \\ \text { 95\% Cl: LL } & 566.5 & 557.5 & 768.1 & 995.9 & 917.1 & 1009.0 & 734.0 & 341.1 & 594.4 & 722.4 \\ \text { 95\% Cl: UL } & 1113.9 & 888.8 & 845.4 & 1998.8 & 1430.3 & 1115.4 & 1136.5 & 635.6 & 634.4 & 759.3 \\ \text { Deaths } & 56 & 118 & 3086 & 79 & 144 & 2885 & 164 & 87 & 6113 & 12,732\end{array}$

Lung diseases excluding lung cancer ${ }^{d}$

\begin{tabular}{|c|c|c|c|c|c|c|c|c|c|c|}
\hline Rate & $81.8^{*}$ & 160.1 & 147.4 & 187.5 & 153.7 & 171.1 & $44.8^{*}$ & $34.3^{*}$ & 52.6 & 94.8 \\
\hline 95\% Cl: LL & 19.3 & 82.4 & 131.2 & 91.3 & 80.8 & 151.4 & 13.1 & 6.9 & 46.8 & 88.7 \\
\hline 95\% Cl: UL & 144.2 & 237.9 & 163.7 & 283.7 & 226.6 & 190.8 & 76.5 & 61.8 & 58.3 & 100.9 \\
\hline Deaths & 7 & 26 & 558 & 15 & 25 & 500 & 9 & 8 & 517 & 1665 \\
\hline
\end{tabular}

Other-cause mortality ${ }^{e}$

$\begin{array}{lllllllllll}\text { Rate } & 310.3 & 549.3 & 465.7 & 560.2 & 548.7 & 722.7 & 789.1 & 378.5 & 479.0 & 520.7 \\ \text { 95\% Cl: LL } & 137.8 & 395.2 & 434.4 & 348.9 & 359.2 & 680.8 & 566.3 & 253.4 & 460.0 & 505.5 \\ \text { 95\% Cl: UL } & 482.8 & 703.4 & 496.9 & 771.5 & 738.3 & 764.6 & 1011.8 & 503.7 & 498.0 & 535.9 \\ \text { Deaths } & 18 & 84 & 1618 & 37 & 60 & 1814 & 101 & 59 & 4327 & 8118\end{array}$

${ }^{a}$ Excluding participants with missing tobacco-use status, poly-users, and users of other tobacco products including pipe, hookah, e-cigarettes, bidi, and cigars. Survey years: 1987, 1991, 1992, 1994, 1998, 2000, 2005, 2010, and 2012-2014

${ }^{b}$ Smoking-related diseases: diseases of heart, malignant neoplasms, chronic lower respiratory diseases, cerebrovascular diseases, diabetes mellitus, and influenza and pneumonia

c SLT-related diseases: diseases of heart, malignant neoplasms, cerebrovascular diseases, diabetes mellitus

${ }^{d}$ Lung diseases excluding lung cancer: chronic lower respiratory diseases, and influenza and pneumonia

e Other-cause mortality: accidents, Alzheimer's disease, nephritis, nephrotic syndrome and nephrosis, and all other causes

* Estimates with relative standard error greater than $30 \%$. Due to unreliable precision, these estimates should be interpreted with caution

along with all other mortality outcomes, the highest death rate is associated with former smokers who switch to SLT use (hereinafter referred to as "switchers"). Also, death rates for dual users are lower compared to both exclusive current smokers and exclusive current SLT users, for ACM, smoking-related diseases and OCM. This could be due to the fact that dual users are on average 3 and 5 years younger than exclusive current smokers and SLT users, respectively (Table 2). Tables S4 and S5 in Additional file 1 show the death rates and the corresponding $95 \% \mathrm{CIs}$, by tobacco-use status and leading cause of death for males and females aged 35+, respectively.

For ACM, Fig. 1 shows the estimated HRs (with never users as reference group) and $95 \%$ CIs, by sex, age group (35-64 and 65+), and tobacco-use status. ACM HRs for male exclusive current smokers for age groups 35-64 and $65+$ were 2.06 (95\% CI: $1.79-2.36)$ and 2.17 (95\% CI: 1.94-2.43), respectively; for male exclusive former smokers for the same age groups, the HRs were 1.31 (95\% CI: $1.09-1.58)$ and 1.35 (95\% CI: $1.24-1.46)$, respectively. ACM HRs for female exclusive current 


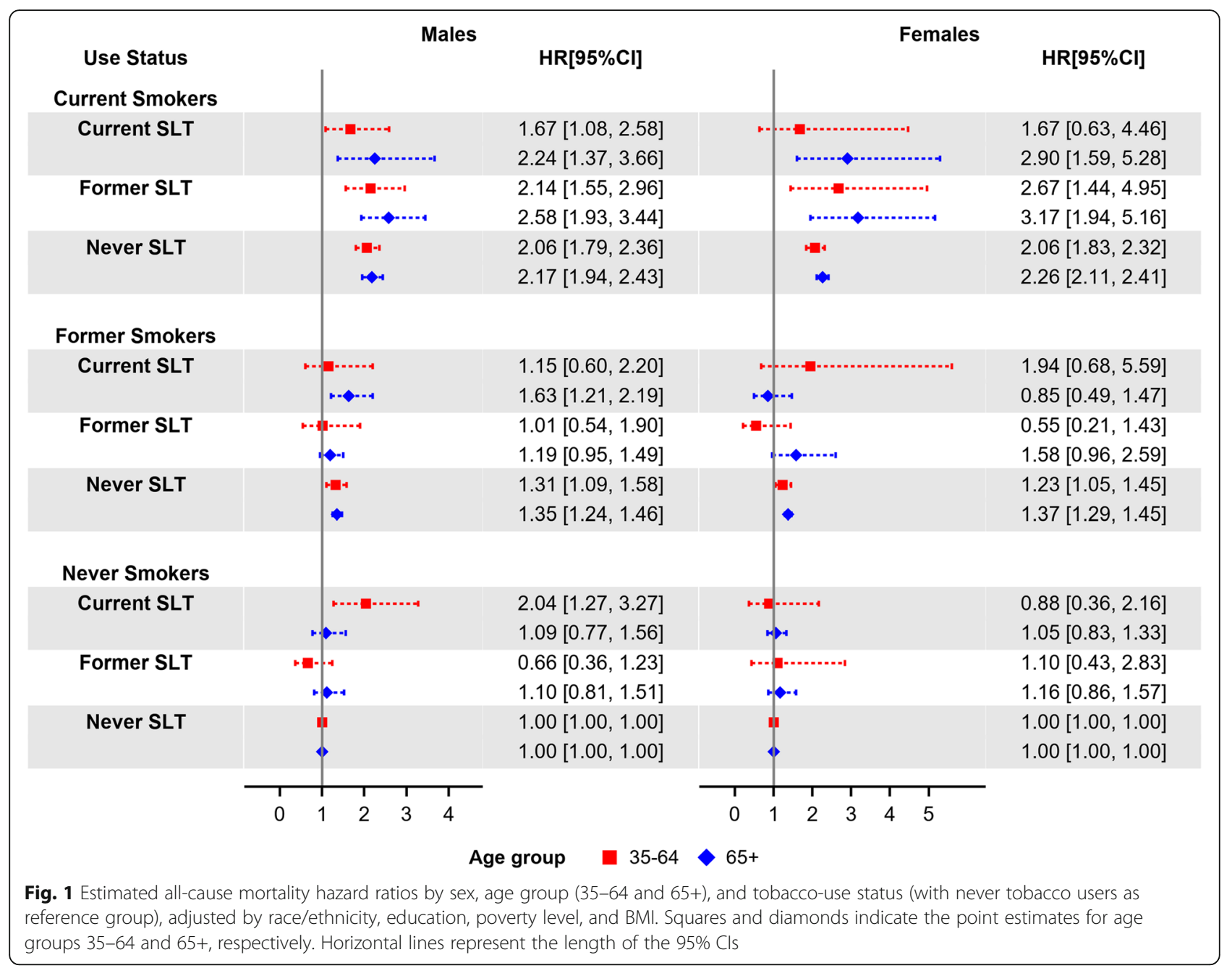

smokers for age groups 35-64 and 65+ were 2.06 (95\% CI: $1.83-2.32$ ) and 2.26 (95\% CI: 2.11-2.41), respectively; for female exclusive former smokers for the same age groups, the HRs were 1.23 (95\% CI: $1.05-1.45$ ) and 1.37 (95\% CI: 1.29-1.45), respectively. Higher values of ACM HRs for both males (HR: 2.58, 95\% CI: 1.93-3.44) and females (HR: 3.17, 95\% CI: 1.94-5.16) aged 65+ were associated with former SLT users who switched to cigarettes. The HR for dual users aged 35-64 was only significant for male users (HR: 1.67, 95\% CI: 1.08-2.58), while the HR for dual users aged $65+$ was significant for both, males (HR: 2.24, 95\% CI: 1.37-3.66) and females (HR: 2.9, 95\% CI: 1.59-5.28). ACM HRs for exclusive current SLT users were only significant for males aged 35-64 (HR: 2.04, 95\% CI: 1.27-3.27). Additional file 1: Table S6, shows the estimated ACM HRs by tobaccouse status, sex, and 10-year age groups; ACM HRs for exclusive current SLT users were significant for male users aged 35-44 (HR: 2.64, 95\% CI: 1.18-5.88), for adults (females and males combined) aged 35-44 (HR:
3.14, 95\% CI: 1.44-6.87), and for adults aged 75-84 (HR: 1.34, 95\% CI: 1-1.81). The ACM HR for switchers was only significant for males aged $65+(\mathrm{HR}: 1.63,95 \% \mathrm{CI}$ : 1.21-2.19).

Figures 2 and 3 show the estimated mortality HRs for smoking-related and SLT-related diseases, respectively; HRs for current smokers, regardless of SLT use status, are comparable with the ACM HR estimates. HRs for exclusive current SLT users were not significant for these two mortality outcomes. Male exclusive former SLT users aged $65+$ had borderline significant HRs of 1.43 (95\% CI: 1.00-2.05) for smoking-related diseases and 1.44 (95\% CI: 0.99-2.11) for SLT-related diseases. Additional file 1: Figure S1, shows estimated OCM HRs; male exclusive current SLT users aged 35-64 had a significant HR of 2.8 (95\% CI: 1.50-5.25). OCM HRs for female and male exclusive current smokers were similar with the ACM HRs through all age groups. Additional file 1: Figure S2, shows the estimated HRs for lung diseases (excluding lung cancer); compared to other 


\begin{tabular}{|c|c|c|c|c|c|c|}
\hline Use Status & \multicolumn{3}{|c|}{ Males } & \multicolumn{3}{|c|}{ Females } \\
\hline \multicolumn{7}{|c|}{ Current Smokers } \\
\hline Current SLT & & (n) & $\begin{array}{l}2.19[1.29,3.72] \\
2.98[1.78,4.96]\end{array}$ & & $\mid$ & $\begin{array}{l}2.40[0.80,7.24] \\
2.98[1.28,6.93]\end{array}$ \\
\hline Former SLT & & 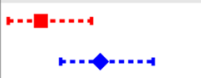 & $\begin{array}{l}1.89[1.20,2.97] \\
3.15[2.32,4.28]\end{array}$ & & $\mid$ & $\begin{array}{l}3.21[1.52,6.81] \\
2.69[1.38,5.25]\end{array}$ \\
\hline Never SLT & & $\rightarrow-1$ & $\begin{array}{l}2.18[1.79,2.65] \\
2.45[2.14,2.79]\end{array}$ & & $\rightarrow$ & $\begin{array}{l}2.11[1.81,2.47] \\
2.66[2.46,2.89]\end{array}$ \\
\hline \multicolumn{7}{|l|}{ Former Smokers } \\
\hline Current SLT & & . & $\begin{array}{l}1.45[0.68,3.09] \\
2.06[1.47,2.88]\end{array}$ & $\cdots$ & -1 & $\begin{array}{l}1.19[0.35,4.06] \\
0.66[0.31,1.40]\end{array}$ \\
\hline Former SLT & & a-....-1 & $\begin{array}{l}1.27[0.60,2.69] \\
1.33[1.04,1.69]\end{array}$ & + & ...-. & $\begin{array}{l}0.57[0.16,1.97] \\
1.99[1.19,3.34]\end{array}$ \\
\hline Never SLT & & -4 & $\begin{array}{l}1.21[0.96,1.53] \\
1.44[1.30,1.59]\end{array}$ & & 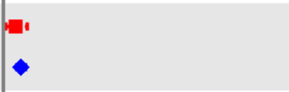 & $\begin{array}{l}1.29[1.06,1.58] \\
1.43[1.33,1.53]\end{array}$ \\
\hline \multicolumn{7}{|l|}{ Never Smokers } \\
\hline Current SLT & & -1 & $\begin{array}{l}1.28[0.67,2.43] \\
1.21[0.82,1.78]\end{array}$ & & 4 & $\begin{array}{l}1.10[0.35,3.43] \\
1.04[0.77,1.41]\end{array}$ \\
\hline Former SLT & ㅁ… & . & $\begin{array}{l}0.40[0.13,1.25] \\
1.43[1.00,2.05]\end{array}$ &. & -.-1 & $\begin{array}{l}0.33[0.08,1.34] \\
1.15[0.74,1.79]\end{array}$ \\
\hline Never SLT & 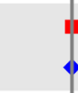 & & $\begin{array}{l}1.00[1.00,1.00] \\
1.00[1.00,1.00]\end{array}$ & & 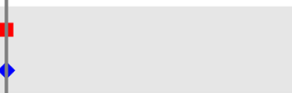 & $\begin{array}{l}1.00[1.00,1.00] \\
1.00[1.00,1.00]\end{array}$ \\
\hline & $\begin{array}{ll}1 \\
0 & 1\end{array}$ & $\begin{array}{lll} & 1 & 1 \\
2 & 3 & 4\end{array}$ & group $\quad 35-64$ & $\begin{array}{r}1+1 \\
01 \\
65+\end{array}$ & $\begin{array}{lllll}1 & 1 & 1 & 1 \\
1 & 2 & 3 & 4 & 5\end{array}$ & \\
\hline $\begin{array}{l}\text { Fig. } 2 \text { Estimated smok } \\
\text { reference group), adjus } \\
\text { groups } 35-64 \text { and } 65+\end{array}$ & $\begin{array}{l}\text { ed } m \\
\text { ace/e } \\
\text { ively. }\end{array}$ & $\begin{array}{l}\text { Iortality hazard rati } \\
\text { athnicity, educatior } \\
\text { Horizontal lines re }\end{array}$ & $\begin{array}{l}\text { ex, age group (35-6 } \\
\text { ty level, and BMI. S } \\
t \text { the length of the }\end{array}$ & $\begin{array}{l}\text { nd } 65+) \text {, } \\
\text { res and } \\
6 \mathrm{Cls}\end{array}$ & $\begin{array}{l}\text {-), and tobacco-use status } \\
\text { diamonds indicate the p }\end{array}$ & $\begin{array}{l}\text { never tobacco users } \\
\text { stimates for age }\end{array}$ \\
\hline
\end{tabular}

mortality outcomes, those estimates had wider 95\% CIs due to the limited number of deaths from lung diseases.

Additional file 1: Table S7, shows the sex-combined HR estimates with their corresponding 95\% CIs for all mortality outcomes for age groups 34-64 and 65+. For smoking-related diseases, the HR for switchers in the $65+$ age category (HR: 2.28, 95\% CI: 1.65-3.14) was significantly higher compared to exclusive former smokers (HR: 1.53, 95\% CI: 1.44-1.62). For SLT-related diseases, and for the $65+$ age group, we also observed a significant difference among switchers (HR: 2.16, 95\% CI: 1.513.09 ) and exclusive former smokers (HR: 1.40, 95\% CI: $1.32-1.49)$.

\section{Discussion}

This analysis extends previous studies that used the NHIS-LMF data and provides updated mortality risk estimates by sex and tobacco-use status considering age groups (35-64, 65+, and 10-year groups), assuming a 10-year mortality follow-up to reduce misclassification of participants' tobacco-use status during the survival time.

Our results are consistent with and contribute to previous findings on mortality risks attributable to cigarette and SLT use in the U.S. population. We observed increased mortality risk for cigarette smokers for all-cause and cause-specific mortality, consistent with previous research [7]. We also observed some evidence of increased mortality risk among exclusive SLT users, specifically for men aged 35-64 and from OCM. These results are generally consistent with previous estimates of increased ACM risk among daily SLT users [13] and sexcombined SLT users [12] that were obtained from NHIS-LMF data. Our results are also consistent with the previous observation of increased mortality risk for other causes among SLT users, especially in the 40-59 age group [12].

Our findings indicate that male exclusive current SLT users aged 35-64 had significant HRs for ACM and OCM. Also, the significant ACM HR was driven 


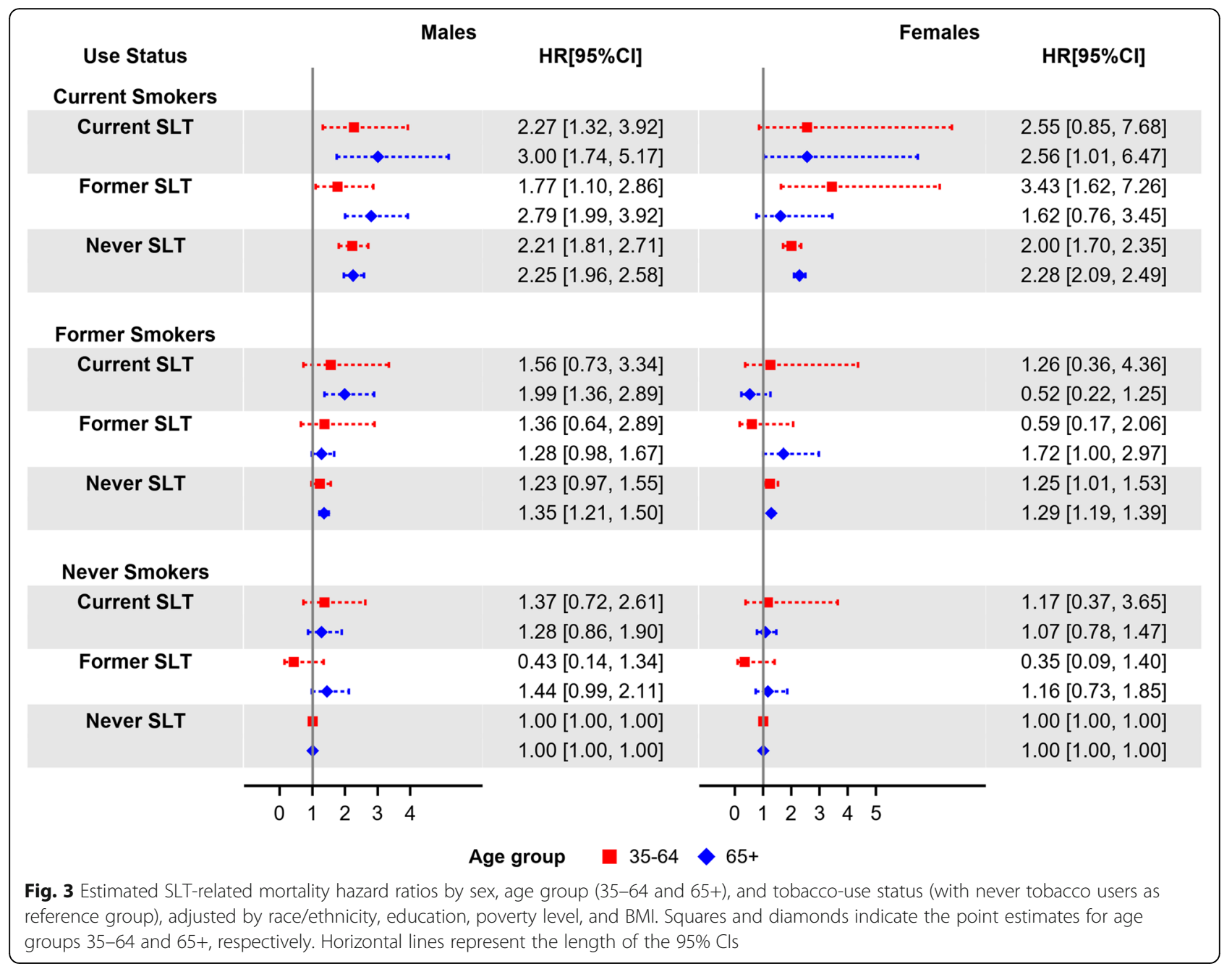

by a significant HR for male users aged 35-44. These results suggest that the elevated ACM HR among young male adults could be associated with other lifestyle factors (e.g., drug overdose, alcohol abuse) besides SLT use behaviors, disease-specific mortality associated with SLT use [10], or other unknown underlying factors that were not controlled for in this study. Male exclusive former SLT users aged 65+ had borderline significant HRs for both smoking-related and SLT-related diseases; however, sex-combined HR estimates were significant for these two mortality outcomes (see Additional file 1: Table S7). These results suggest that people may quit SLT use when they start experiencing major health conditions at older ages. Male dual users had elevated significant HRs for ACM, smoking-, and SLT-related diseases for age groups 35-64 and 65+; for these three mortality outcomes, HRs for female dual users were only significant in the 65+ age category. Sex-combined HRs estimates for dual users were significant for both age groups. For smoking- and SLT-related diseases, sexcombined mortality HRs were significantly higher for switchers aged 65+ compared to exclusive former smokers, with non-overlapping CIs between the two tobacco-use groups. These results were largely driven by the elevated HRs for male switchers and exclusive former smokers aged $65+$. Although we observed significant risk differences between switchers and exclusive former smokers in older adults, those results did not account for smoking-related behavior for quitters (e.g., tobacco-use intensity, years of smoking, and quitting time) that may need to be considered to understand this finding.

Studies from other countries have shown that a large number of deaths worldwide were attributed to SLT use, with a large proportion in the Southeast Asian region [37-39]. Mortality estimates from nationally representative cohort studies, as presented in our study, would be 
beneficial in regions with high SLT-related mortality risk and prevalence.

\section{Limitations}

This study is subject to the following limitations. First, self-reported tobacco-use data collected at the time of interview did not account for changes on tobacco-use status over participants' lifetimes; thus, we used a maximum of 10-year mortality follow-up to reduce misclassification of participants' tobacco-use status during the survival time. We also conducted a sensitivity analysis comparing results from various follow-up periods $(5,10,15,20$, and up to 29 years), but results did not differ substantially (see Additional file 1: Table S8). Second, the sample size and number of reported deaths for exclusive current and former SLT users was limited due to low prevalence of SLT use across years; thus, we observed higher standard errors and wider 95\% CIs compared to smokers. Third, this study did not include tobacco-use intensity, duration of use, quitting time, insurance status, and geographic information (urban/rural) as covariates in our models since these data were either not available for both cigarettes and SLT users in all the survey years analyzed or only available in the restricteduse NHIS data. Fourth, the criteria used to define former and never SLT users could potentially allow for misclassification of the two groups since it roughly categorized respondents who had ever used SLT less than 20 times in their lifetime and did not use it around the time of interview as former SLT users. Fifth, other health risk factors such as alcohol abuse, drug overdose, physical activities, hypertension, and diabetes were only available in some years of NHIS and were not controlled for in this study.

Further, although there were some changes in the SLT product landscape during the study period (such as the introduction of other forms of SLT like snus and dissolvables), this study did not explore how these product changes affect risk estimates. Lastly, although we presented mortality risk estimates by selected leading cause of death, our study did not explore disease-specific risk mortality outcomes (available in the restricted-use NHIS-LMF data). However, the low sample size for current and former SLT users would still be a limitation for disease-specific data analysis. Analysis of larger populations of SLT users and availability of data from more survey years, including SLT use behaviors, could enable more reliable conclusions on SLT-related mortality risk.

\section{Conclusions}

For ACM, both male and female exclusive current smokers had significantly higher HRs than exclusive former smokers. For males aged 35-64, exclusive current SLT users had a significant ACM HR (2.04, 95\% CI: 1.27-3.27), which was driven by an elevated HR for male exclusive current SLT users aged 35-44 (2.64, 95\% CI: 1.18-5.88). Also, male exclusive current SLT users aged 35-64 had an elevated significant OCM HR (2.8, 95\% CI: 1.5-5.25). Mortality HRs for female exclusive SLT users were not significant regardless of the underlying cause of death and likely due to the relatively small sample size for female SLT users. These results provide updated mortality risk estimates to assess the mortality impact of cigarettes and SLT products in the U.S. population, and may inform regulatory activities such as tobacco product standard development and product application reviews.

\section{Abbreviations}

SLT: Smokeless tobacco; HR: Hazard ratio; ACM: All-cause mortality; OCM: Other-cause mortality; NLMS: National Longitudinal Mortality Study; NDI: National Death Index; NHIS: National Health Interview Survey; LMF: Linked Mortality Files; BMI: Body mass index; Cl: Confidence interval

\section{Supplementary Information}

The online version contains supplementary material available at https://doi. org/10.1186/s12889-021-11801-w.

\begin{abstract}
Additional file 1: Table S1. Available tobacco products and data file type from NHIS data. Table S2. Underlying cause of death categories included on the public-use 2015 NHIS-LMF and derived mortality outcomes used for analysis. Table S3. Demographic and socioeconomic characteristics (weighted estimates and 95\% Cls) for NHIS participants aged $35+$ at the time of interview. ${ }^{a}$. Table S4. Death rates (per 100,000 person-years), $95 \% \mathrm{Cls}$, and number of deaths by leading cause of death among male adults aged 35+ using a maximum of 10-year follow-up. ${ }^{\text {. }}$. Table S5. Death rates (per 100,000 person-years), 95\% Cls, and number of deaths by leading cause of death among female adults aged 35+ using a maximum of 10-year follow-up. . Table S6. Estimated all-cause mortality hazard ratios (HRs) and $95 \%$ Cls by sex, 10-year age groups, and tobacco-use status (with never tobacco users as reference group), adjusted by race/ethnicity, education, poverty level, and BMI. Maximum mortality follow-up: 10 years. Table S7. Sex-combined hazard ratio (HR) estimates and $95 \%$ Cls by mortality outcome, age groups, and tobaccouse status (with never tobacco users as reference group), adjusted by race/ethnicity, education, poverty level, and BMI. Maximum mortality follow-up: 10 years. Table S8. Estimated all-cause mortality hazard ratios (HRs) and 95\% Cls by years of follow-up, sex, age groups, and tobaccouse status (with never tobacco users as reference group), adjusted by race/ethnicity, education, poverty level, and BMI. Figure S1. Estimated other-cause mortality hazard ratios by sex, age group (35-64 and 65+), and tobacco-use status (with never tobacco users as reference group), adjusted by race/ethnicity, education, poverty level, and BMI. Squares and diamonds indicate the point estimates for age groups 35-64 and 65+, respectively. Horizontal lines represent the length of the $95 \% \mathrm{Cls}$. Figure S2. Estimated mortality hazard ratios for lung diseases (excluding lung cancer) by sex, age group (35-64 and 65+), and tobacco-use status (with never tobacco users as reference group), adjusted by race/ethnicity, education, poverty level, and BMI. Squares and diamonds indicate the point estimates for age groups 35-64 and 65+, respectively. Horizontal lines represent the length of the $95 \%$ Cls.
\end{abstract}

\section{Acknowledgments}

This work was previously presented at the Society for Research on Nicotine \& Tobacco (SRNT) 26th Annual Meeting, on March 2020. The authors would like to thank Deborah Neveleff for assistance with technical editing. 


\section{Authors' contributions}

$E S, C R$ and BR conceptualized the study. ES and CR conducted data analyses and led the writing of the manuscript. BR provided feedback on data analysis and interpretation of results, as well as reviewed and edited the manuscript. GS provided feedback and reviewed the manuscript. All authors read and approved the final manuscript.

\section{Funding}

This work was funded by the Center for Tobacco Products, U.S. Food and Drug Administration. The findings and conclusions in this paper are those of the authors and do not necessarily represent the official position of the Food and Drug Administration.

\section{Availability of data and materials}

The 2015 Public-Use Linked Mortality Files used and analyzed during the current study are publicly available through the Centers for Disease Control and Prevention website: https://www.cdc.gov/nchs/data-linkage/mortalitypublic.htm

\section{Declarations}

\section{Ethics approval and consent to participate}

Not applicable.

\section{Consent for publication}

Not applicable.

\section{Competing interests}

The authors declare that they have no competing interests.

Received: 7 April 2021 Accepted: 13 September 2021

\section{Published online: 29 September 2021}

\section{References}

1. Food and Drug Administration (FDA). Harmful and potentially harmful constituents in tobacco products and tobacco smoke; established list. Fed Regist 2012;77(64):20034-20037.

2. National Cancer Institute (NCl), Centers for Disease Control and Prevention (CDC). Smokeless Tobacco and Public Health: A Global Perspective. Bethesda, MD: U.S. Department of Health and Human Services, Centers for Disease Control and Prevention and National Institutes of Health, National Cancer Institute. NIH Publication No. 14-7983; 2014.

3. National Center for Chronic Disease Prevention and Health Promotion (US) Office on Smoking and Health. The Health Consequences of Smoking-50 Years of Progress: A Report of the Surgeon General. 13, Patterns of Tobacco Use Among U.S. Youth, Young Adults, and Adults. Atlanta (GA): Centers for Disease Control and Prevention (US); 2014. https://www.ncbi.nlm.nih.gov/ books/NBK294302/\#ch13.s4. Accessed 19 Aug 2020.

4. Cancer Trends Progress Report: Behavioral factors, adult tobacco use. National Cancer Institute, NIH, DHHS. Bethesda, MD. 2020. https:// progressreport.cancer.gov/prevention/adult_smoking. Accessed 15 Nov 2020.

5. U.S. Federal Trade Commission (FTC). Federal Trade Smokeless Tobacco Report for 2018. Washington: Federal Trade Commission 2019. https://www. ftc.gov/system/files/documents/reports/federal-trade-commission-cigarettereport-2018-smokeless-tobacco-report-2018/p114508smokelesstoba ccoreport2018.pdf. Accessed 15 Nov 2020.

6. Jha P, Ramasundarahettige C, Landsman V, Rostron B, Thun M, Anderson RN, et al. 21st-century hazards of smoking and benefits of cessation in the United States. N Engl J Med. 2013;368(4):341-50. https://doi.org/10.1056/ NEJMsa1211128.

7. Thun MJ, Carter BD, Feskanich D, Freedman ND, Prentice R, Lopez AD, et al. 50-year trends in smoking-related mortality in the United States. N Engl J Med. 2013;368(4):351-64. https://doi.org/10.1056/NEJMsa1211127.

8. Inoue-Choi M, Liao LM, Reyes-Guzman C, Hartge P, Caporaso N, Freedman ND. Association of long-term, low-intensity smoking with all-cause and cause-specific mortality in the National Institutes of Health-AARP diet and health study. JAMA Intern Med. 2017;177(1):87-95. https://doi.org/10.1001/ja mainternmed.2016.7511.

9. Henley SJ, Thun MJ, Connell C, Calle EE. Two large prospective studies of mortality among men who use snuff or chewing tobacco (United States).
Cancer Causes Control. 2005;16(4):347-58. https://doi.org/10.1007/s10552004-5519-6.

10. Timberlake DS, Nikitin D, Johnson NJ, Altekruse SF. A longitudinal study of smokeless tobacco use and mortality in the United States. Int J Cancer. 2017;141(2):264-70. https://doi.org/10.1002/ijc.30736.

11. Fisher MT, Tan-Torres SM, Gaworski CL, et al. Smokeless tobacco mortality risks: an analysis of two contemporary nationally representative longitudinal mortality studies. Harm Reduct J. 2019;16:27.

12. Rodu B, Plurphanswat N. Mortality among male smokers and smokeless tobacco users in the USA. Harm Reduct J. 2019:16:50.

13. Inoue-Choi M, Shiels MS, McNeel TS, et al. Contemporary associations of exclusive cigarette, cigar, pipe, and smokeless tobacco use with overall and cause-specific mortality in the United States. JNCI Cancer Spect. 2019;3:3.

14. National Center for Health Statistics. Office of Analysis and Epidemiology, Public-use Linked Mortality File. Hyattsville, Maryland. 2015. https://www. cdc.gov/nchs/data-linkage/mortality-publichtm. Accessed 19 Aug 2020.

15. National Center for Health Statistics. Survey Description, National Health Interview Survey, 2017. Hyattsville, Maryland. 2018.

16. National Center for Chronic Disease Prevention and Health Promotion (US) Office on Smoking and Health. The Health Consequences of Smoking-50 Years of Progress: A Report of the Surgeon General. 11, General Morbidity and All-Cause Mortality. Atlanta (GA): Centers for Disease Control and Prevention (US); 2014. https://www.ncbi.nlm.nih.gov/books/NBK294300/. Accessed 22 Mar 2021.

17. U.S. Department of Health and Human Services. Smoking Cessation: A Report of the Surgeon General-Executive Summary. Atlanta, GA: U.S. Department of Health and Human Services, Centers for Disease Control and Prevention, National Center for Chronic Disease Prevention and Health Promotion, Office on Smoking and Health; 2020. https://www.hhs.gov/sites/ default/files/2020-cessation-sgr-executive-summary.pdf. Accessed $22 \mathrm{Mar}$ 2021.

18. Anderson RN, Minino AM, Hoyert DL, et al. Comparability of cause of death between ICD-9 and ICD-10: Preliminary estimates. National Vital Statistics Reports; Vol 49 No.2. National Center for Health Statistics: Hyattsville; 2001.

19. Molgaard CA, Bartok A, Peddecord KM, Rothrock J. The association between cerebrovascular disease and smoking: a case-control study. Neuroepidemiology. 1986;5(2):88-94. https://doi.org/10.1159/000110818.

20. Bishaw A, Iceland J. Census 2000 Brief. Washington, DC: US Dept. of Commerce, Economics and Statistics Administration, US Census Bureau; 2003.

21. Proctor BD, Semega JL, Kollar MA. U.S. Census Bureau, Current Population Reports, P60-256(RV), Income and Poverty in the United States: 2015. Washington, DC: U.S. Government Printing Office; 2016.

22. Rogers RG, Powell-Griner E. Life expectancies of cigarette smokers and nonsmokers in the United States. Soc Sci Med. 1991;32(10):1151-9. https:// doi.org/10.1016/0277-9536(91)90092-Q.

23. Levy PS, Lemeshow S. Sampling of Populations: Methods and Applications. 4th ed: Wiley; 2008.

24. Selvin S. Survival analysis for epidemiologic and medical research Cambridge University press; 2008. https://doi.org/10.1017/CBO978051161 9809

25. Binder DA. Fitting Cox's proportional hazards models from survey data. Biometrika. 1992;79(1):139-47. https://doi.org/10.1093/biomet/79.1.139.

26. Lyn DY. On fitting Cox's proportional hazards models to survey data. Biometrika. 2000;87(1):37-47. https://doi.org/10.1093/biomet/87.1.37.

27. Inoue-Choi M, Christensen CH, Rostron BL, Cosgrove CM, Reyes-Guzman C, Apelberg $B$, et al. Dose-response association of low-intensity and nondaily smoking with mortality in the United States. JAMA Netw Open. 2020;1(6): e206436. https://doi.org/10.1001/jamanetworkopen.2020.6436.

28. Liu X. Survival analysis: models and applications: Wiley; 2012. https://doi. org/10.1002/9781118307656.

29. Rao JNK, Scott AJ. On chi-squared tests for multiway contingency tables with cell proportions estimated from survey data. Ann Stat. 1984;12(1):46-60.

30. Lumley T, Scott A. Partial likelihood ratio tests for the cox model under complex sampling. Stat Med. 2013;32(1):110-23. https://doi.org/10.1002/sim. 5492.

31. SAS 9.4. SAS Institute Inc. Cary, NC.

32. R Core Team. R: A Language and Environment for Statistical Computing. R Foundation for Statistical Computing. Vienna, Austria 2019.

33. Lumley T. Complex surveys: a guide to analysis using R: John Wiley and Sons; 2010. https://doi.org/10.1002/9780470580066. 
34. Lumley T. survey: analysis of complex survey samples. R package version 3 . 36. 2019.

35. Korn EL, Graubard Bl. Analysis of health surveys. New York: John Wiley \& Sons; 1999. https://doi.org/10.1002/9781118032619.

36. Oranje A. Confidence Intervals for Proportion Estimates in Complex Samples. ETS Research Report Series. 2006;2006(2):i-26.

37. Sinha DN, Suliankatchi RA, Gupta PC, Thamarangsi T, Agarwal N, Parascandola M, et al. Global burden of all-cause and cause-specific mortality due to smokeless tobacco use: systematic review and metaanalysis. Tob Control. 2018;27(1):35-42. https://doi.org/10.1136/toba ccocontrol-2016-053302.

38. Sinha DN, Palipudi KM, Gupta PC, et al. Smokeless tobacco use: a metaanalysis of risk and attributable mortality estimates for India. Indian J Cancer. 2014;51(Suppl1):S73-7.

39. Gajalakshmi V, Kanimozhi V. Tobacco chewing and adult mortality: a casecontrol analysis of 22,000 cases and 429,000 controls, never smoking tobacco and never drinking alcohol, in South India. Asian Pac J Cancer Prev. 2015;16(3):1201-6. https://doi.org/10.7314/APJCP.2015.16.3.1201.

\section{Publisher's Note}

Springer Nature remains neutral with regard to jurisdictional claims in published maps and institutional affiliations.

Ready to submit your research? Choose BMC and benefit from:

- fast, convenient online submission

- thorough peer review by experienced researchers in your field

- rapid publication on acceptance

- support for research data, including large and complex data types

- gold Open Access which fosters wider collaboration and increased citations

- maximum visibility for your research: over $100 \mathrm{M}$ website views per year

At BMC, research is always in progress.

Learn more biomedcentral.com/submissions 